\title{
Current Opinions on ISO 9001 Quality Management System: Evidence from Poland
}

\author{
Piotr ROGALA \\ Wrocław University of Economics, Wrocław, Poland \\ piotr.rogala@ue.wroc.pl
}

\begin{abstract}
The aim of the paper is to identify and analyze the current opinions concerning the usefulness of the ISO 9001 quality management system among people (from small and medium enterprises) who are not directly involved into activities connected with implementing, maintaining and improving the systems. The survey was completed by 34 people including 29 representing manufacturing companies, and the remaining 5 represent service companies. The biggest group were executive directors (13 people), the second place was shared by owners and co-owners ( 8 people) and directors ( 8 people). The smallest group were the specialists ( 5 people). The research has proven that ISO 9001 quality management system is a management system that is widely used, and also gained recognition in business environment. This claim is confirmed by the fact that as many as 18 (from 34 included in the research) organizations were certified with ISO 9001. Additionally, all respondents (also those, who represented organizations without such certification) declared they knew what ISO 9001 quality management system is. It may also be assumed that the popularity of quality management system will not decrease in the nearest future despite the changes introduced to the standard in 2015.
\end{abstract}

Keywords: ISO 9001, Quality Management System, Small and Medium Enterprises.

\section{$1 \quad$ Introduction}

The ISO 9001:2015 international standard sets out the criteria for a quality management system (QMS). It has been one of the most commonly implemented management methods in the last two decades. The standard requires that an organization has verifiable routines and procedures in place for product design, manufacture, delivery, service and support. Under ISO 9001 an organization must monitor strictly the sequence of steps it takes for the completion of a job. For this purpose, it must follow process documentation. To guarantee compliance with the standard's requirements, third-party auditors evaluate an organization's procedures and carry out site visits. The end-result is supposed to be an improvement in the organization's performance [10].

A new revision on ISO 9001 standard was published in 2015. Organizations were granted a three-year transition period (until September 2018) to migrate from their 
ISO 9001 QMS to the new edition of the standard. Facing this change, it is worth to consider the future of the international standard ISO 9001. Will the number of certificates grow, decrease in next few years or it will remain at the same level? The factor, which will definitely influence the forming of the phenomenon is the way of assessing the quality management system in business environment. Although the professional literature provides numerous results of research carried out among people directly engaged in the functioning of the quality management system in organizations (i.e. management representatives, quality managers, auditors, etc.), it is hard to find any that cover the rest of an organization's employees. The aim of the article is to identify and analyze the current opinions concerning the usefulness of the quality management system ISO 9001 among people who are not directly involved into activities connected with implementing, maintaining and improving the quality management systems. It concerns both, the ISO 9001 certified organizations as well as those which have not implemented or certified the QMS yet but may decide to do it in the future.

\section{Theoretical Background}

The International Organization for Standardization (ISO) first published the ISO 9001 international standard in 1987, and since then it has undergone four amendments. The changes introduced in 1994, focused on a global approach to the life cycle of a product - from the customer's needs to the moment of the actual use of the product. The amendments of the 2000 simplified the standard's structure but most importantly included a number of crucial changes concerning the scope and content of the requirements. The revision also exchanged the term "quality system" with "quality management system". The next review, took place in 2008. It introduced minor changes meant to clarify some issues and also increase the conformity with ISO 14001 standard. In September 2015, a new version of the ISO 9001 was published. It shows many differences compared to the version of 2008. These changes imply various challenges to companies. They are mostly concerning the standard's structure, the dealing with external and internal parties, the process orientation, the support of the top management, the knowledge management and the dealing with risks and opportunities. From 2015, there is a 'High-Level-Structure', which is effective for all future ISO management system standards to make a standardized handling and a simplified integration of different management systems possible. Regarding the collaboration, the term 'interested parties' is introduced, which need to be defined individually by every organization. To do so, the external and internal parties' needs and expectations with influence on the company's QMS are closely examined. Furthermore, processes including input and output as well as the corresponding process key figures need to be clearly defined. Also, the top management is held increasingly responsible regarding the QMS' effectiveness. Within the knowledge management, there is an extended demand concerning the employees' competency development. This way, the knowledge of the employees is focalized more strongly, and the competency development will be thoroughly documented. One of the main 
modifications is the risk-based approach, which requires companies to plan and realize measures to treat risks and opportunities [14].

In the past 26 years of ISO 9000 series standards existence, they have reach great popularity. The International Organization for Standardization (ISO) have carried out studies which prove that in 2017 as many as 1058504 organizations worldwide had a certified ISO 9001 quality management system. The biggest number of certificates stating the conformity with ISO 9001 was issued in: China, Italy, Germany, Japan, the UK, Spain, India, the USA, France and Brazil [8]. The fact of certain stabilization in the number of ISO 9001 certificates has also been confirmed [see Table.1].

Table 1. The number of ISO 9001 certificates [8].

\begin{tabular}{crrrrrrr}
\hline Year & 2011 & 2012 & 2013 & 2014 & 2015 & 2016 & 2017 \\
\hline $\begin{array}{c}\text { Number } \\
\text { of } \\
\text { certificates }\end{array}$ & 1009845 & 1017279 & 1022877 & 1036321 & 1034180 & 1105937 & 1058504 \\
\hline
\end{tabular}

The quality management systems are proved by many surveys to be highly effective $[3,5,17,18]$. However, it should be noted that there have appeared a number of publications pointing out some problems. [1,7].

Definitely worth noticing is that the majority of the articles base on opinions of people directly responsible for quality management systems. They are mainly management representatives and auditors. What is more, in many case of numerous articles, the authors do not provide detailed characteristics of the respondents. They only inform that the answers come from a specific group of organizations e.g. small and middle-sized companies [3,9]. It may be assumed that the responses in those cases also came from people directly dealing with quality management systems in the companies. The image of the systems of quality management created in this way may have a subjective character. Therefore it should be supplemented with information/opinions from other sources. One of the biggest groups which need to be included is organizations' representatives (especially the managers) who are not directly responsible for the functioning of the quality management system. In the nearest future, their opinions will significantly influence the maintenance of ISO 9001 systems in certified organizations and the implementation in organizations which have not done it before.

\section{$3 \quad$ Research Methodology}

For the needs of the following research a proper survey was prepared. It formulates 7 statements concerning ISO 9001 quality management system, i.e.:

1. Implementing ISO $9001 \mathrm{QMS}$ organizes the activity of an organization.

2. Implementing ISO 9001 QMS increases competitiveness.

3. Implementing ISO 9001 QMS increases reliability of a company - they are willingly chosen as suppliers, cooperators etc. 
4. Implementing ISO 9001 QMS is forced by e.g. customers, cooperators, local, regional and state authorities etc.

5. Implementing ISO 9001 QMS makes the products/services more likely to buy.

6. Implementing ISO 9001 QMS increases an organization's chances to receive financial help (donations, EU funding etc.)

7. Implementing ISO 9001 QMS in an organization leads to tangible quality increase of products and services.

The task of the respondents was to grade all of them using a 7-point scale from 1 to 7 where 1 means definitely not while 7 means definitely yes.

The second part of the survey included questions characterizing the respondents. Auditorium questionnaire was chosen as the research method. This technique is a form of measurement suitable for application during such events as conferences, symposia, lectures, trade shows. The research involves distributing questionnaires to its participants, and after answering the questions - an interviewer collects the completed questionnaires. The possibility of measurement control is an advantage of the auditorium questionnaire, which enables to achieve a huge percentage of answers and to preserve anonymity at the same time [6].

The annual symposium of SIMP association was held on March 2018. The organization incorporates the leading small and medium enterprises (mostly manufacturing industries) from the region of Jelenia Góra, Poland. The aim of the association is to initiate, maintain and support cooperation among its members. The symposium was visited by 43 members who were included in the research. The survey was completed by 34 people including 29 representing manufacturing companies, and the 5 represent service companies. The biggest group were the executive directors (13 people), the second place was shared by owners and coowners ( 8 people) and directors ( 8 people). The smallest group were the specialists (5 people). More than a half of the respondents represented ISO 9001 certified organizations (18 organizations). It is interesting that all respondents claimed to be familiar with ISO 9001. Grading the statement „I know what ISO 9001 quality management is", 14 people answered "rather yes", 13 marked the "yes" answer and the remaining 7 chose answer "definitely yes".

\section{$4 \quad$ Research Results}

In the research process the respondents were asked to grade 7 statements concerning ISO 9001 quality management system. The statements were formulated on the basis of literature review $[2,3,4,5,7,12,14,15,17,18]$.

The first of them was formulated as follows: „Implementing ISO 9001 quality management system organizes the activity of an organization". The distribution of the answers is shown in Fig.1. 


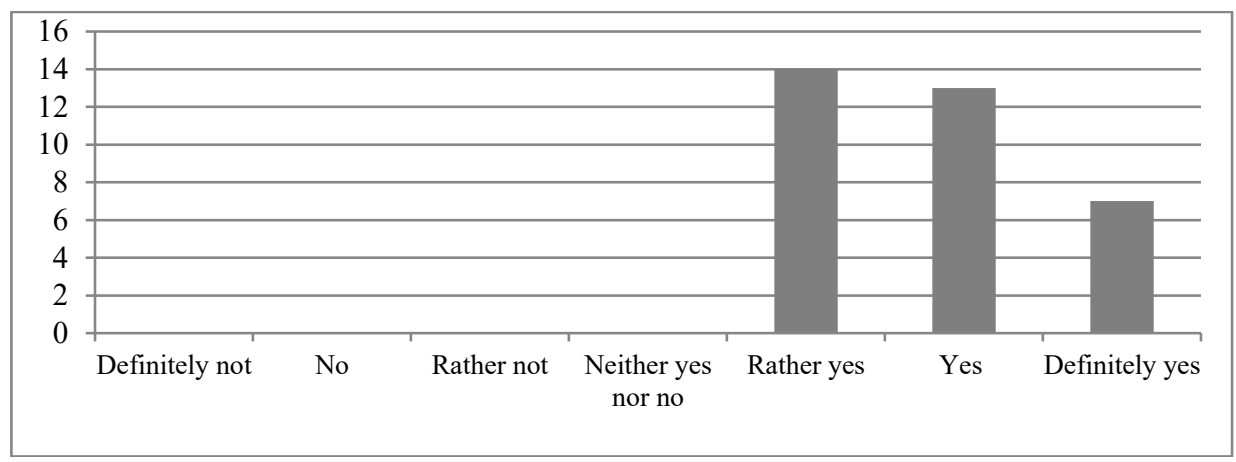

Fig. 1. The distribution of the answers concerning statement "implementing ISO 9001 quality management system organizes the activity of an organization".

The second statement was expressed in this way: „Implementing ISO 9001 quality management system increases competitiveness". The distribution of the answers is shown in Fig.2.

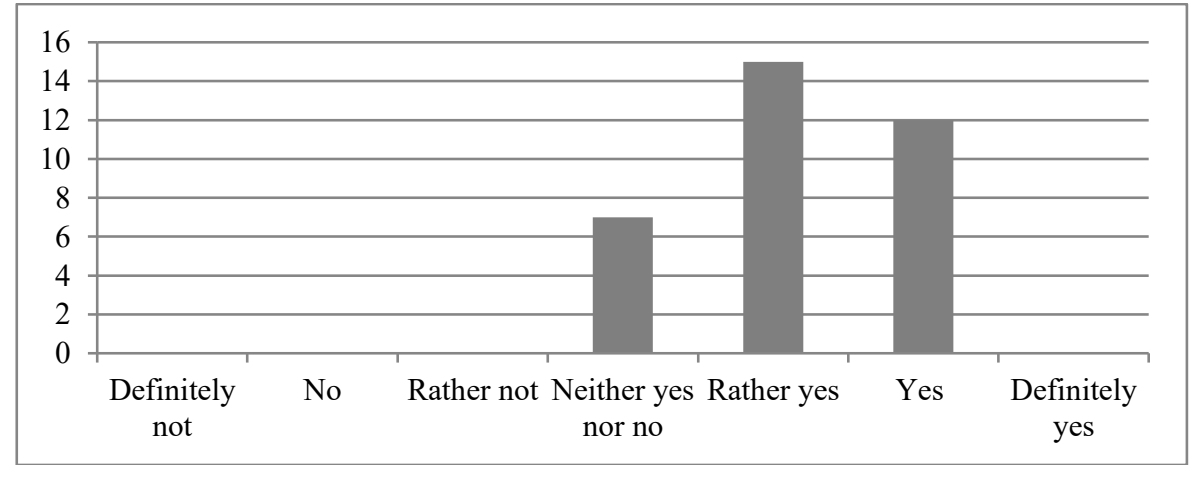

Fig. 2. The distribution of the answers concerning statement "Implementing ISO 9001 quality management system increases competitiveness".

The next issue concerned the reliability of an organization. The distribution of answers concerning statement „Implementing ISO 9001 quality management system increases reliability of a company - they are willingly chosen as suppliers, cooperators etc." is presented in Fig.3. 


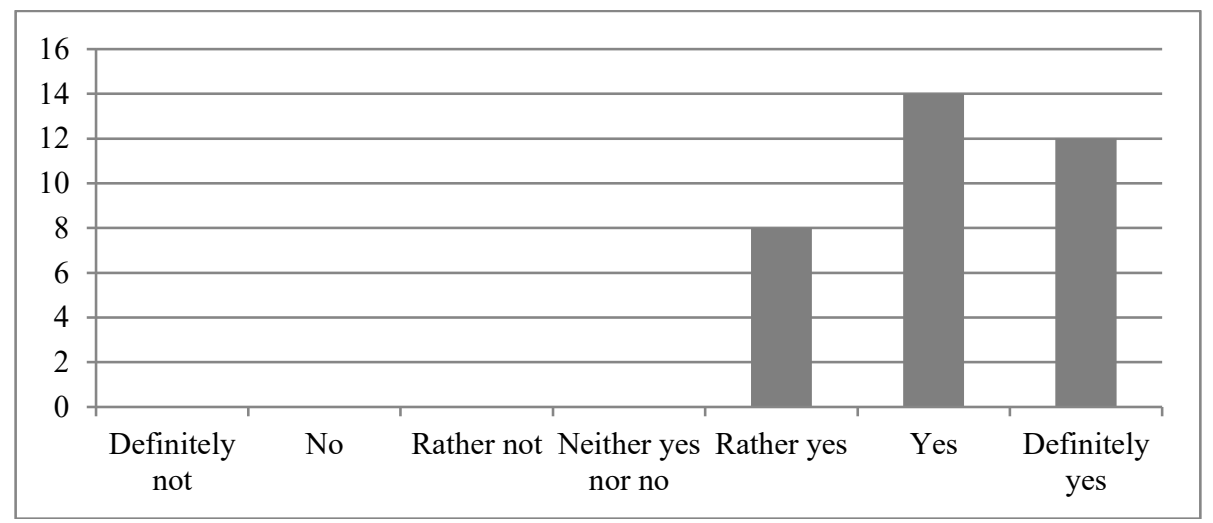

Fig. 3. The distribution of the answers concerning statement "Implementing ISO 9001 quality management system increases reliability of a company - they are willingly chosen as suppliers, cooperators etc."

The fourth issue was defined as „Implementing ISO 9001 quality management system is forced by e.g. customers, cooperators, local, regional and state authorities etc". The distribution of the received answers is shown in Fig.4.

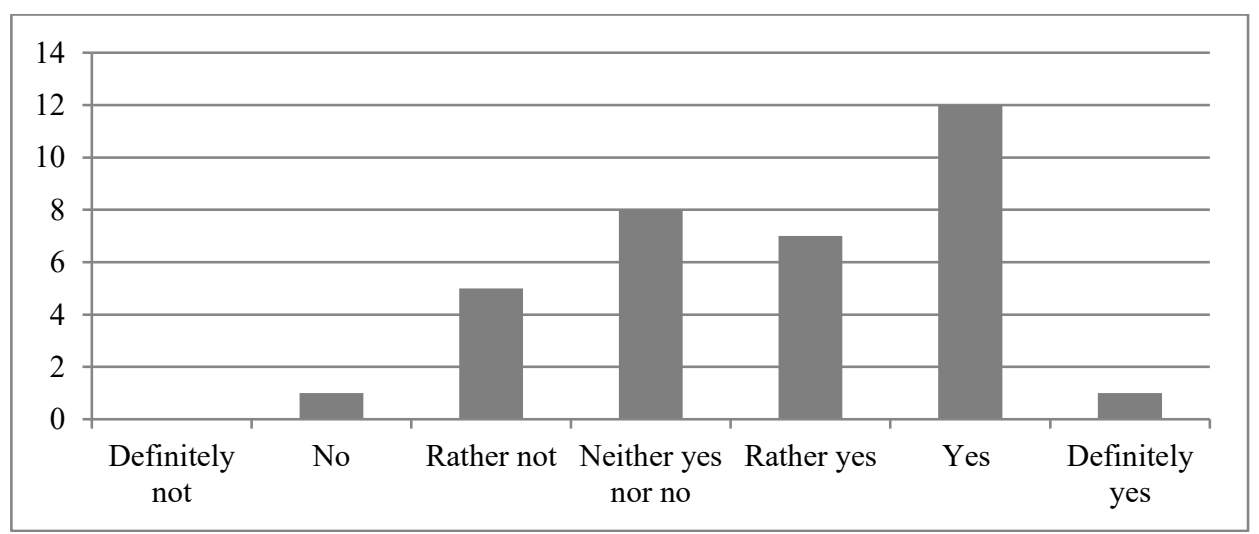

Fig. 4. The distribution of the answers concerning statement „Implementing ISO 9001 quality management system is forced by e.g. customers, cooperators, local, regional and state authorities etc."

The next statement is defined in the following way: „Implementing ISO 9001 quality management system makes the products/services more likely to buy". The distribution of the received answers is shown in Fig.5. 


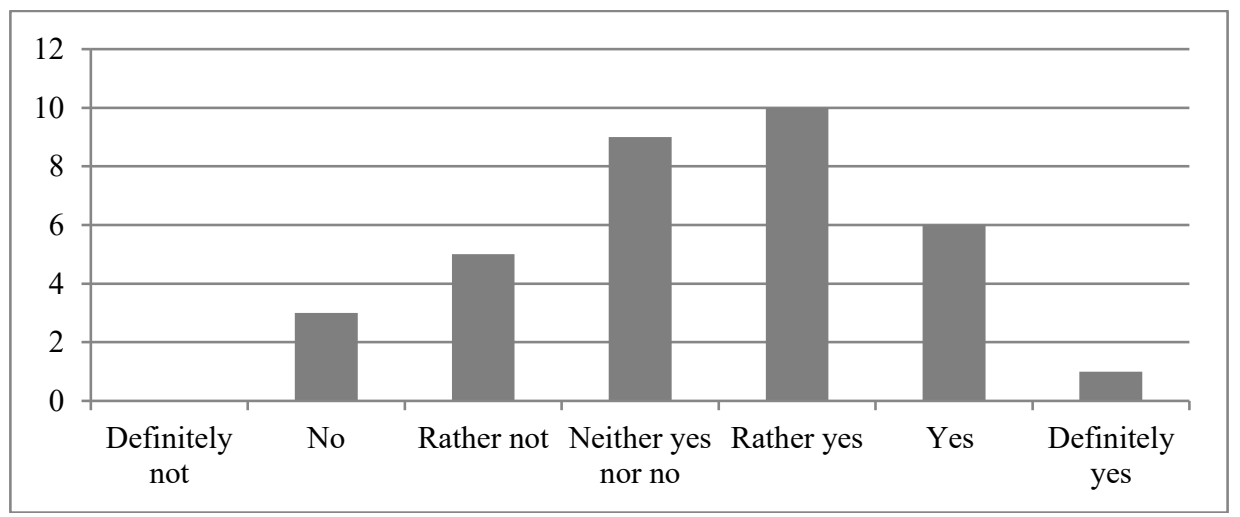

Fig. 5. The distribution of the answers concerning statement „Implementing ISO 9001 quality management system makes the products/services more likely to buy.

The sixth issue also concerned the incentives for implementing a quality management system. It was defined as follows: „Implementing ISO 9001 quality management system increases an organization's chances to receive financial help (donations, EU funding etc.)". The distribution of the received answers is shown in Fig.6.

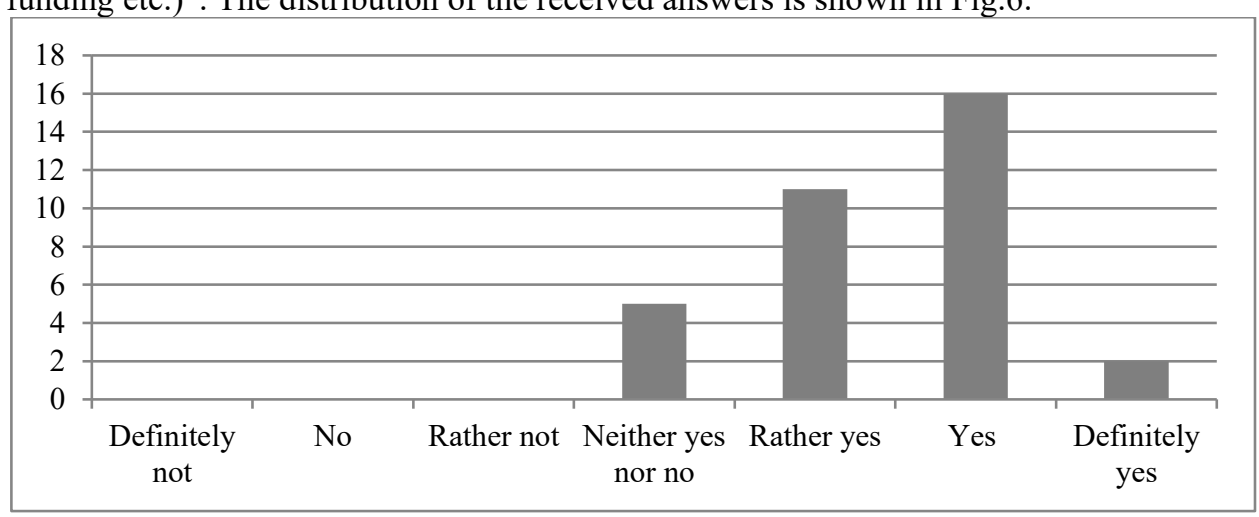

Fig. 6. The distribution of the answers concerning statement „Implementing ISO 9001 quality management system increases an organization's chances to receive financial help.

The last statement included in the survey was expressed in the following way: "Implementing ISO 9001 quality management system in an organization leads to tangible quality increase of products and services". The distribution of the received answers is shown in Fig.7. 


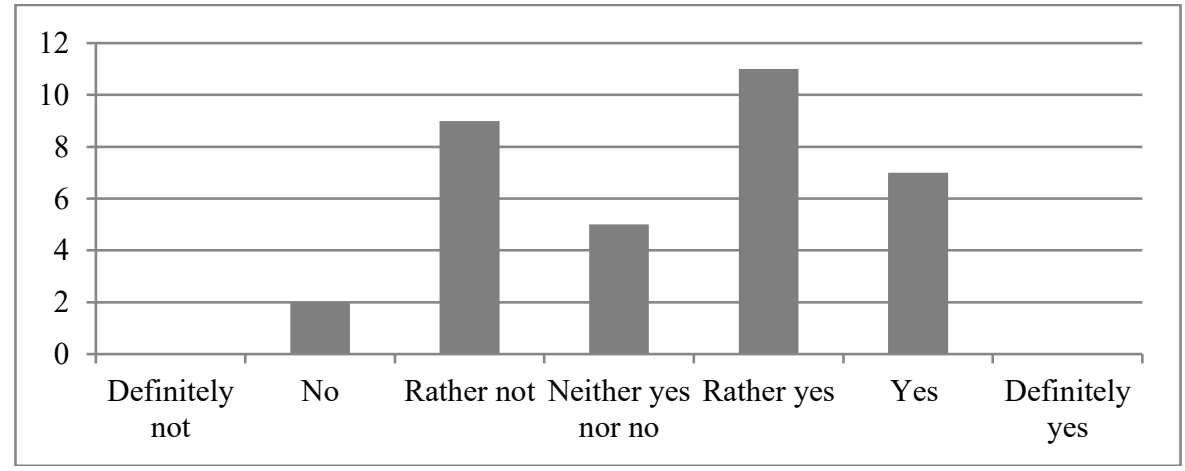

Fig. 7. The distribution of the answers concerning statement „Implementing ISO 9001 quality management system in an organization leads to tangible quality increase of products and services.

\section{Discussion}

The carried-out research confirms opinions that ISO 9001 quality management system is a management tool which is currently recognizable and used in business environment $[4,11]$. This claim is confirmed by the fact that as many as 18 (from 34 included in the research) organizations were certified with ISO 9001. Additionally, all respondents (also those, who represented organizations without such certification) declared they knew what ISO 9001 quality management system is. Almost $60 \%$ claimed that the level of their knowledge of the topic is good or very good. Also, the results published by ISO show that the number of valid certificates remains at a stable level exceeding 1 million. Although they noted a drop of this rate in 2017 in comparison to the previous year, when analyzing the number of valid certificates in a 7 years span it is clear that such changes are natural characteristics of the issue.

The second conclusion which may be formulated on the basis of the carried-out research concerns the evaluation of the usefulness of ISO 9001 quality management system. All benefits connected with QMS which were included in the survey were confirmed by business representatives. This conclusion is in the line with the results of the research carried out by Rusjan and Alič, which prove, that ISO 9001 QMS has a positive influence on the relations with customers, internal processes of the organization, development of the organization and financial results [13]. Average evaluation of the benefits connected with ISO 9001quality management system (the respondents graded every benefit in 1-7 scale). 
Table 2. Evaluation of the benefits resulting from ISO 9001 quality management system.

\begin{tabular}{lc}
\hline Benefits resulting from ISO 9001 QMS & Average grade \\
\hline Organizing the organization's activities & 6.21 \\
Reinforcing credibility & 6.12 \\
Improving chances for receiving financial help & 5.44 \\
Improving competitiveness & 5.15 \\
Increase in the sale of products or services & 4.41 \\
Real increase in the quality of products/services & 4.35 \\
\hline
\end{tabular}

The image of ISO 9001 received from the results of the research does not confirm appearing in professional literature opinions that the attractiveness of the quality management system has recently diminished [16] or that in the small and medium enterprises it has a limited usefulness [11].

The respondents also claimed that certain entities (i.e. clients, cooperators, authorities) put pressure on organizations in order to persuade them to implement and maintain ISO 9001 quality management system. The average evaluation of the statement "Implementing ISO 9001 quality management system is forced by e.g. customers, cooperators, local, regional and state authorities etc" was set at 4.79.

Summarizing, it may be claimed that ISO 9001 quality management system is a method of management which is commonly used in business and is appreciated by the business environment. Therefore, it is possible to conclude that in spite of changes introduced in ISO 9001standard in 2015 the popularity of this solution in the next few years will not significantly change.

\section{Conclusions}

The purpose of the study was to find out and analyze the opinions concerning usefulness of ISO 9001 quality management system of the business representatives who are not directly involved in activities connected with implementing, maintaining or improving the quality management systems. The research has proven that ISO 9001 QMS is a management method that is widely used, and also gained recognition in business environment. It may also be assumed that the popularity of quality management system will not decrease in the nearest future despite the changes introduced to the standard in 2015.

Like other this type studies, the research has some limitations. First of all the research covered organizations from one country only while ISO 9001 quality management system is globally used. Therefore, the group of respondents should be extended to include representatives of other countries. Secondly, the research bases on opinions of people representing organizations with ISO 9001 certification and those with no certificate of the type. It seems reasonable to divide the two groups to verify whether they significantly differ in their opinions. Thirdly, while providing the answers, the respondents were driven by their personal impressions (e.g. in the range of their ISO 9001 knowledge). Therefore, it is necessary to perform additional studies 
in order to make the image more objective. However, it must be remembered that those subjective opinions are very important too, as they influence decisions concerning implementing or maintenance of quality management system. The last limitation is including only SME in the research, whereas the big organizations, especially international concerns mainly set trends in the area of quality management and certification.

\section{References}

1. Boiral, O., Amara, N.: Paradoxes of ISO 9000 performance - a configurational approach. Quality Management Journal 16(3), 36-60 (2009), DOI: https://doi.org/10.1080/14783363.2010.532330.

2. Casadesús, M., Gimènez, G., Heras, I.: Benefits of ISO 9000 implementation in Spanish industry. European Business Review 13(6), 327-335 (2001), DOI: https://doi.org/10.1108/EUM0000000006195.

3. Casadesús, M., Giménez, G.: The benefits of the implementation of the ISO 9000 standard: empirical research in 288 Spanish companies. The TQM Magazine 12(6), 432441(2000), DOI: https://doi.org/10.1108/09544780010351751.

4. Ferreira, C., Salgado, E., Silva, C., Mello, C., Sampaio P.: Reasons and benefits associated with ISO 9001 certification for sugar and ethanol companies. Independent Journal of Management \& Production 6(3), 623-642 (2015), DOI: 10.14807/ijmp.v6i3.301.

5. Fonseca, L., Domingues J., Machado, P., Calderón, M.: Management System Certification Benefits: Where Do We Stand?. Journal of Industrial Engineering and Management 10(3), 476-494 (2017), DOI: https://doi.org/10.3926/jiem.2350.

6. Gębarowski, M., Siemieniako, D.: Mystery visitor as a research method of trade show performance. Economics and Management 7(3), 15-24 (2015), DOI: 10.12846/j.em.2015.03.02.

7. Heras-Saizarbitoria, I., Casadesús, M., Marimón, F.: The impact of ISO 9001 standard and the EFQM model: The view of the assessors. Total Quality Management 22(2), 197-218 (2011), DOI: https://doi.org/10.1080/14783363.2010.532330.

8. ISO Survey, https://www.iso.org/the-iso-survey.html, Last Accessem 2017/10/11.

9. Murmura F., Bravi L.: Empirical evidence about ISO 9001 and ISO 9004 in Italian companies. The TQM Journal 29(5), 650-665 (2017), DOI: https://doi.org/10.1108/TQM11-2016-0097.

10. Naveh, E., Marcuz, A., Moon, H.: Implementing ISO 9000: performance improvement by first or second movers. International Journal of Production Research 42(9), 1843-1863 (2004), DOI: 10.1080/00207540410001662912.

11. Poksinska B., Eklund, J., Dahlgaard, J., J.: ISO 9001:2000 in small organisations: Lost opportunities, benefits and influencing factors, International Journal of Quality \& Reliability Management 23(5), 490-512 (2006), DOI: https://doi.org/10.1108/02656710610664578.

12. Prado, C., Castillo, C., Mercado, C., Castillo, J.: The effects of implementing ISO 9001 in the Spanish construction industry. Cuadernos de Gestión 18(1), 149-172 (2018), DOI: $10.5295 / \mathrm{cdg} .140507 \mathrm{~cd}$.

13. Rusjan, B., Alič, M., Capitalising on ISO 9001 benefits for strategic results. International Journal of Quality \& Reliability Management 27(7), 756-778, DOI: https:// doi.org/10.1108/02656711011062372. 
14. Rybski, C. Jochem, R. \& Homma, L.: Empirical study on status of preparation for ISO 9001:2015. Total Quality Management \& Business Excellence 28(9-10), 1076-1089 (2017), DOI:10.1080/14783363.2017.1303886.

15. Sampaio, P., Saraiva, P., Rodrigues, A.: The economic impact of quality management systems in Portuguese certified companies: Empirical evidence. International Journal of Quality \& Reliability Management 28(9), 929-950 (2011), DOI: https://doi.org/10.1108/02656711111172522.

16. Simon, A., Kafel, P.: Reasons for Decertification of iso 9001. An Empirical Study. Innovar 28(70), 69-80 (2016). DOI: 10.15446/innovar.v28n70.74 449.

17. Tarí J., J., José Francisco Molina-Azorín, J., F., Heras, I.: Benefits of the ISO 9001 and ISO 14001 standards: A literature reviewJournal of Industrial Engineering and Management. 5(2), 297-322 (2012), DOI: http://dx.doi.org/10.3926/jiem.488.

18. To, L., Yu, B.: Benefits of implementing management system standards: A case study of certified companies in the Pearl River Delta, China. The TQM Journal 24(1), 17-27 (2011), DOI: https://doi.org/10.1108/17542731211191195. 